\title{
Review of the Afrotropical subgenus Disneyempis (Diptera: Empididae)
}

\author{
Christophe DAUGERON \\ ESA 8043 CNRS, Laboratoire d'Entomologie, Muséum national d'Histoire naturelle, 45 rue Buffon, 75005 Paris, France; \\ e-mail: daugeron@mnhn.fr
}

Key words. Taxonomy, Diptera, Empididae, Empis, Disneyempis, new species, phylogeny, monophyly, Afrotropical region

\begin{abstract}
The Afrotropical subgenus Disneyempis Smith of the genus Empis L. is redescribed and redefined on the basis of three synapomorphies, namely labrum lengthened, male eyes more or less broadly separated on frons with all ommatidia of equal size, female abdomen with bluish to purplish metallic reflections on terga 2-5. At present, the subgenus comprises six species: $E$. (D.) hirsutipennis Smith as type species, E. (D.) jacksoni Smith, E. (D.) argentea sp. n., E. (D.) spinifemorata sp. n., E. (D.) proboprocera sp. n. and one unnamed species $E$. (D.) sp. 1. All species are described [except $E$. (D.) sp. 1] and keyed. The subgenus has a tropical African geographical range including Cameroon, Democratic Republic of Congo (formerly Zaire), Republic of Congo and Gabon.
\end{abstract}

\section{INTRODUCTION}

Dance flies of the tribe Empidini (Empididae: Empidinae) form a large worldwide group of about 1,200 described species. Two very large genera, Rhamphomyia Meigen, 1822 and Empis L., 1758, contain some $90 \%$ of described species. A subgeneric classification based on the Palaearctic fauna has been established for these two genera (Bezzi, 1909). However, as Chvála (1994) pointed out, this subgeneric classification is hardly applicable to other geographical regions and several subgenera appear unnatural. Nevertheless, the subgeneric classification has been partly followed for the Afrotropical fauna by Smith (1967a, b, 1969, 1971, 1976, 1980), who published the only significant work on the regional Empidinae. Species in which wing vein $\mathrm{M} 1$ or veins $\mathrm{M} 1$ and $\mathrm{M} 2$ are abbreviated were placed in the subgenus Coptophlebia Bezzi, 1909 (Empis) and species with all median veins complete in Empis s. str. Four species were placed in the genus Rhamphomyia without subgeneric placement. For a unique species, Empis hirsutipennis Smith, represented by a single female from Cameroon, Smith (1976) established a new subgenus Disneyempis of the genus Empis on account of the presence of three unique characters: A bluish metallic abdomen, a radial fork (vein R4+5) lengthened with an acute angle, and densely microtrichiate wings.

As Chvála (1994) already noted, redefinition of the subgenera Empis s. str. and Coptophlebia is needed, for at least two reasons: First, the abbreviation of vein M1 is present also in species belonging to other groups, e.g. $E$. (Kritempis) livida L.; second, the complete/abbreviated vein M1 is a polymorphic character, since some specimens of Enipis s. str. show an abbreviated M1 and conversely some specimens of Coptophlebia a complete M1. Consequently, the subgenera are not well defined even for the Palaearctic region. To clarify these taxonomic problems, Palaearctic Empis s. str. and Coptophlebia have been divided already into several inferred monophyletic groups (Syrovátka, 1991; Chvála, 1994). Amongst these changes, the name of Coptophlebia becomes reserved for a small Palaearctic group of six species (Chvála, 1994; Daugeron, 1997b,c).

With the aim of proposing a future phylogenetic analysis of the tribe Empidini, a comparable study has been performed for the Afrotropical Empidini for which six groups were tentatively identified, of which one is represented also in the Oriental and Australasian regions (Daugeron, 1997c, 1999; Appendix). This paper presents a revision of one of this group, the subgenus Disneyempis, comprising six closely related species: $E$. hirsutipennis Smith, the type-species of the subgenus Disneyempis, E. jacksoni Smith (described in the subgenus Coptophlebia: Smith, 1971) the female of which is newly described here, as well as four new species. To attest its monophyly, this group was compared with all groups considered previously by any author as potential relatives.

\section{MATERIAL AND METHODS}

\section{Assessment of the monophyly of Disneyempis}

According to previous phylogenetic and taxonomic studies (Syrovátka, 1991; Chvála, 1994; Daugeron, 1997c and in prep.) and cladistic analysis of important material from Palaearctic and Afrotropical regions (Daugeron, 1997c and in prep.), several species-groups, including Disneyempis, seem to form a monophyletic lineage within the tribe Empidini on the basis of a slender, strongly sclerotized proboscis, especially the labium, and other characters in the venation. Consequently, the monophyly of Disneyempis was preferably assessed by comparison with members of this group as follows:

First, a list of 13 species-groups was compiled. This list comprises 12 species-groups belonging either to Empis s. str. or Coptophlebia, as well as the subgenus Aclonempis Collin, 1926 of the genus Rhamphomyia since this subgenus is considered to be more related to Empis s. str. and Coptophlebia than to other members of Rhamphomyia (see for example Chvála, 1994). Second, morphological comparison was made between species of Disneyempis and remaining groups. Considering the current ideas of the phylogeny of the entire tribe Empidini, the characters found only in Disneyempis appear to be synapomorphic and support monophyly of that taxon. 


\section{Material and morphological terms}

This study is mainly based on pinned adult specimens belonging to collections of Diptera of the Muséum national d'Histoire naturelle, Paris (MNHN), the Natural History Museum, London (BMNH), the Natal Museum, Pietermaritzburg and the Royal Belgian Institute of Natural Sciences, Brussels.

The morphological terms follow McAlpine (1981), except for the male genital sclerites, the interpretation of which follows Sinclair et al. (1994) and Cumming et al. (1995). Consequently the traditional male genital terms of dorsal, lateral and ventral lamellae are replaced by cerci, epandrium and hypandrium respectively. However, as already explained (Daugeron, 1997a), the term epandrial lamella is used for the lateral sclerites forming the epandrium. In all descriptions, the length of labrum is given relative to head height.

The male genitalia and female postabdomen were dissected and macerated in hot $10 \% \mathrm{KOH}$; specimens were drawn in glycerine using a camera lucida.

\section{MONOPHYLY OF DISNEYEMPIS}

Three synapomorphies were found to attest the monophyly of the subgenus Disneyempis: The length of the labrum, the arrangement of eyes and size of ommatidia in male, and the coloration of the female abdomen. Of the characters originally given by Smith (1976) to define the subgenus Disneyempis, only the coloration of the female abdomen is thus retained. The other two characters (radial fork lengthened and microtrichiate wings) therefore are without subgeneric significance.

First, the labrum is always very long, between 3.5 and 5 times the head height ( $=5$ to 7 times the head width). In all other groups examined (Appendix), the labrum often is longer than the head but rarely more than twice; in a few species like Empis pennipes L. the labrum is about three times the head height.

Second, eyes of known males are either distinctly separated on the frons, although less than in females, or only separated by a narrow space, thus almost holoptic; the upper ommatidia are never enlarged, and all ommatidia are of equal size or lower ommatidia a little enlarged.

Holoptic eyes with upper ommatidia enlarged, which is hypothesized to represent the ground plan condition in the Empidoidea (Wiegmann et al. 1993), are present in males of other groups examined (Appendix). Nevertheless, as the arrangement of eyes is homoplastic within the Empidoidea (Sinclair, 1995; Daugeron, 1999), the dichoptic eyes with all ommatidia of equal size or lower ommatidia a little enlarged is only tentatively considered synapomorphic for species of Disneyempis.

Third, the female abdomen exhibits bluish to purplish metallic reflections on terga 2-5. This character is proposed only as a possible additional synapomorphy for Disneyempis, as the females of two species are yet unknown. Also it is tentatively hypothesized that the colour or tint of Disneyempis species changes during life. I found three females of $E$. (C.) jacksoni in the MNHN collections. The first one was collected with a male at Dimonika (Congo) on 12 April 1975. Its abdomen is only shining brown and both specimens are brown in general colour but not very dark. Two days later (on 14 April), at the same place, four specimens, two males and two fe- males, were collected. These specimens are also brown in general colour, but distinctly darker and the females exhibit a metallic abdomen. Although I cannot rule out female polymorphism, the hypothesis of colour change during the life of the fly seems more likely.

A few other Empidini exhibit metallic reflections, namely species of two Neotropical genera, Lamprempis Wheeler \& Melander, 1901 and Porphyrochroa Melander, 1927 (Rafael \& Cumming, 1998), and one Neotropical species of the genus Empis, E. fulvicollis Collin, 1933. These taxa are not closely related to Disneyempis on account of several morphological differences especially in the structure of the proboscis. In addition, metallic reflections are present in both sexes in these species contrary to species of Disneyempis in which only females are metallic. I consider therefore metallic reflections present in species of Disneyempis on the one hand and some Neotropical species on the other hand as homoplastic.

Thus the subgenus Disneyempis seems to represent a monophyletic group of six species within the tribe Empidini. Nevertheless the confirmation of this hypothesis requires collecting of additional specimens and the discovery of missing sex in some species.

\section{SYSTEMATIC ACCOUNT}

\section{Genus Empis L., 1758}

\section{Subgenus Disneyempis Smith, 1976}

Empis (Disneyempis) Smith, 1976: 189.

TYPE SPICHLS: Empis (Disneyempis) hirsutipennis Smith, 1976: 190 (original designation).

INCLUDED SPLCILS: E. (D.) argentea sp. n.; E. (D.) spinifemorata sp. n.; E. (D.) hirsutipennis Smith, 1976; E. (D.) jacksoni Smith, 1971; E. (D.) proboprocera sp. n.; E. (D.) sp. 1 .

Diagnosis. Species of medium to large size, brown in general colour, abdominal terga of females partly metallic with bluish to purplish reflections, only shining in juvenile specimens, with strong, long black bristles (except for the yellow-brown pennate bristles of fore male tarsi present in two specimens of E. spinifemorata). Male eyes broadly separated on frons or only separated by a narrow space, ommatidia of equal size or lower ommatidia somewhat enlarged. Labrum very long, slender, strongly sclerotised, labium with characteristic annulations. Pilosity very developed, especially in males: strong, often very long black bristles on scutum and legs. Laterotergite with fan of long bristles. Costa ending at R5, R4+5 forked, discal cell strongly truncate. Male cercus bifid at tip or lengthened posteriorly, hypandrium almost paired, consisting of two lamellae only connected in subapical point.

Male. Head with lower margin of face sometimes lengthened. Flagellum with three flagellomeres, second and third more or less long. Labrum always very long, prementum and labella with characteristic annulations on the anterolateral and outer margins respectively, labella slender, strongly sclerotised, bare. Eyes distinctly separated on frons (E. jacksoni, E. spinifemorata) or only separated by narrow space (E. argentea, E. probo- 
procera), all ommatidia of equal size or lower ommatidia enlarged.

Thorax with minute silvery pubescence on scutum ( $E$. argentea), with black bristles. Proepisternum bare. Prosternum with distinct, not very long lateral bristles. Acrostichals present or absent ( $E$. argentea and $E$. proboprocera), always absent in prescutellar depression. Dorsocentrals uni- to biserial, strong, very long posteriorly. At least 2 supraalars, 1-3 notopleurals, always 1 postalar, at least 2 apical scutellars, all these bristles strong, very long. Laterotergite with fan of numerous strong, long bristles. Spiracles black-brown.

Legs with femora with more or less fine bristles, especially on mid femur in ventral position. Tibiae and tarsi with distinct bristles, often strong, long on first tarsomere, more or less spine-like on second.

Wing (Figs 5, 8, 14) with $\mathrm{C}$ ending at R5, R4 short, R4+5 right-angled. Discal cell strongly truncate. M1, M2 and Al complete, evanescent or distinctly abbreviated before wing margin. Anal lobe well or weakly developed (E. argentea and $E$. proboprocera).

Abdomen with marginal bristles distinct, black. Sternum 8 well developed distally (Fig. 11), with invaginated posterior membrane at least in D. jacksoni (Fig. 9).

Hypopygium (Figs 1-4, 9-13, 15, 16) with cercus lengthened posteriorly (E. argentea, E. proboprocera, Figs 2, 13), bifid at apical tip (E. spinifemorata, E. jacksoni, Figs 10, 16). Epandrial lamella of specific shape, connected ventrally in E. proboprocera (Fig. 11). Hypandrium well developed posteriorly, narrowly associated to phallus, almost paired: divided in two lamellae only connected in subapical point (Fig. 3), well sclerotised. Phallus more or less thin, not very long (Figs 4, 9, 11, 15). Subepandrial sclerite very broad in dorsal view, strongly sclerotised. All bristles black.

Length. Body 4.3-11.5 mm, wing 5-9 mm.

Female. Similar to male except for the following characters: Eyes dichoptic with frons as broad as face, lower ommatidia enlarged. Pilosity less developed, especially on legs and abdomen. In E. hirsutipennis, wings densely microtrichiate, R4 long, R4+5 lengthened with acute angle (Smith, 1976: 193, Figs 1-3). Terga 2-5 metallic with bluish to purplish reflections, only shining brown in juveniles. Postabdomen normal with cercus unmodified $(E$. jacksoni, E. spinifemorata); distinctly longer than broad, uniformly covered with fine, short bristly-hairs, or modified (E. hirsutipennis, $E$. sp.1); segment 8 somewhat enlarged, tergum 8 with a medioanterior desclerotised part, cercus reduced, weakly sclerotised, with few bristly-hairs only at tip (Figs 6,7 ). A single unsclerotised spermatheca resembling membranous sac.

Length. Body 4.5-10.5 mm, wing 5.6-8.5 mm.

Distribution. Central Africa (Fig. 19): Cameroon, Democratic Republic of Congo (formerly Zaire), Republic of Congo, Gabon. The subgenus seems strictly tropical in its distribution. No specimens of Disneyempis are known from the southern part of Africa.

Remarks. Disneyempis can be distinguished from the E. (Coptophlebia) chrysocera- and E. (C.) namwamba- groups by its three synapomorphies as well as the absence of pennate bristles on legs of females. Disneyempis also differs from the remaining studied Empidini especially by the presence of distinct annulations on the labium and the membranous spermatheca.

\section{Empis (Disneyempis) argentea sp. $\mathrm{n}$.}

Species of medium size, brown with silvery reflections on scutum, fore coxae and mid tibiae. Acrostichals absent. Strong, long bristles on scutum, legs and the two first abdominal terga. Abdominal segments rather shining. Anal lobe weakly developed (Fig. 5).

\section{Male}

Head. Occiput dark brown with row of rather fine postocular bristles. Ocellar triangle with distinct pair of bristles. Frons dark brown, rather shining, reduced, somewhat enlarged above antennae. Face brown, shining. Scape and pedicel brown, first flagellomere brown, lighter at base, long (five times length of pedicel), second and third flagellomeres brown, almost as long as scape. Labrum long (almost four times the head height), brown, labium with characteristic annulations, labella brown-yellow, slender, palpus not visible. Eyes only separated on frons by narrow space, lower ommatidia slightly enlarged.

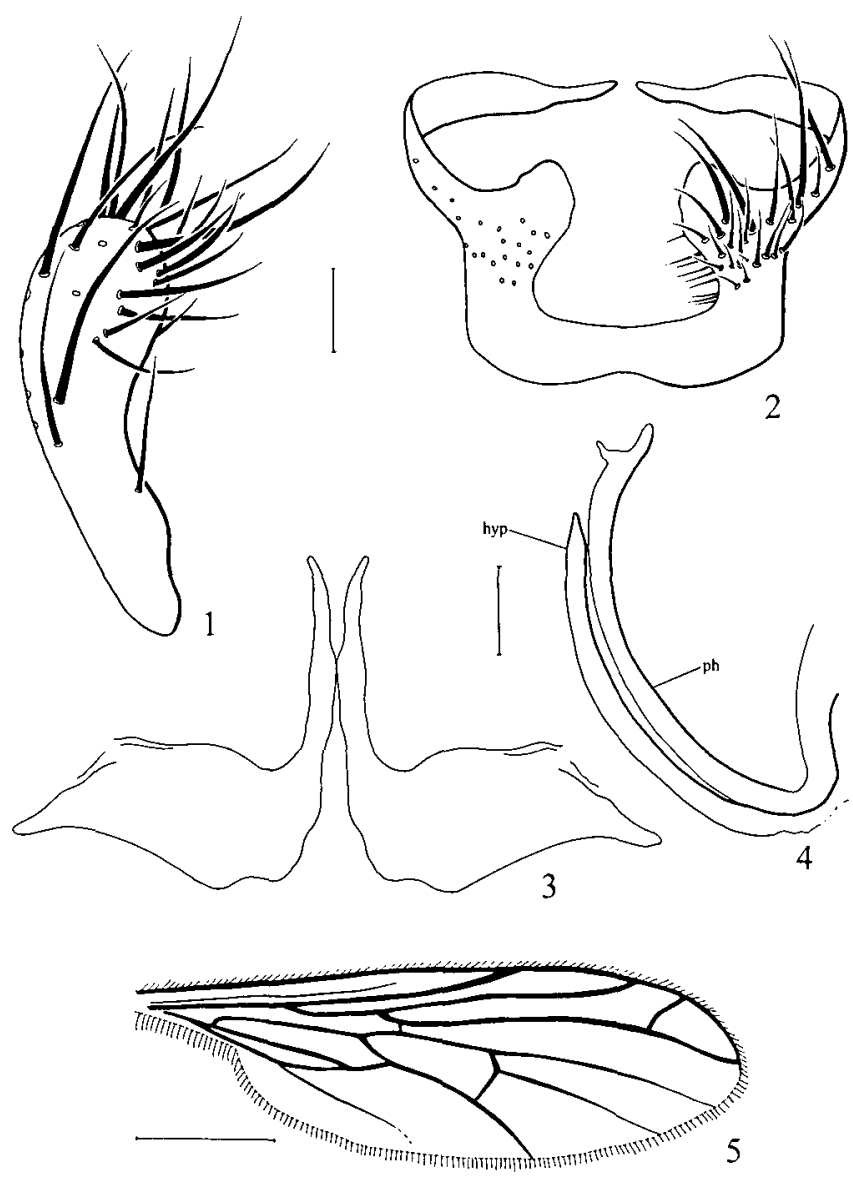

Figs 1-5: E. (D.) argentea sp. n. 1 - epandrial lamella in dorsal view; 2 - cerci in dorsal view; 3 - hypandrium opened in dorsal view; 4 - hypandrium and phallus in lateral view; 5 - left wing. hyp - hypandrium; ph - phallus. Scales: $1-4-0.1 \mathrm{~mm}$; 5 $-1 \mathrm{~mm}$. 
Thorax. Antepronotum brown with 1 row of about 12 distinct bristles. Postpronotal lobes brown with 1 strong, long basal bristle and a few finer and shorter. Proepisternum bare, prosternum with 4 distinct bristles. Scutum with minute silvery pubescence. Acrostichals absent except for 1 short bristle at middle. Dorsocentrals uniserial, absent anteriorly, strong, very long except for the first finer, shorter pair. Intraalar absent. One row of 4 strong, very long supraalars. One notopleural less strong and long than supraalars. Postalar calli with 1 strong, very long bristle, and in front of this, a second one, shorter and finer. Scutellum brown, with 2 strong, very long apical bristles and 2 shorter, finer subapicals. Mediotergite brown. Laterotergite brown, with fan of about 5 strong, very long bristles as well as a few finer. Anterior and posterior spiracles black-brown.

Legs. Fore coxa yellow-brown with silvery minute pubescence anteriorly. Fore femur extensively yellow becoming brown at apex. Fore tibia brown-yellow, fore tarsi black-brown. Mid coxa and femur brown, mid tibia brown with minute anterolateral silvery pubescence in apex. Mid tarsi black-brown. Hind femur extensively yellow becoming brown dorsally and at apex. Hind tibia and tarsi dark brown. All tibiae more or less dilated at apex. All femora with short dorsal bristles, almost bare ventrally with only 6 to 7 fine bristles at basal half. Fore tibia with strong, long dorsal bristles except at base and 2 very long bristles at apex. Mid tibia with 4 strong, long ventral bristles, 3 strong, very long anterodorsals at apical 2/3 and 1 row of numerous rather short posterodorsals. Hind tibia with numerous strong, long dorsal and ventral bristles. Fore and hind first tarsomere long, the former almost as long as the next 4 together and the latter 1.5 times the length of the next 4 together; both with numerous strong, long bristles, hind first tarsomere in particular with ventral spine-like bristles. First tarsomere of mid tarsi with fine, not very long posteroventral bristles in basal half and several very strong, spine-like, longer ventrals. Other tarsomeres with a few strong bristles especially at apical tip.

Wing (Fig. 5) brown. Sc abbreviated. $\mathrm{Ml}$ and $\mathrm{M} 2 \mathrm{com}$ plete, distinctly less sclerotised at tip, A1 evanescent towards the margin of wing. Anal lobe not very developed, consequently anal angle obtuse. Haltere yellow.

Abdomen. First segment and anterior half of second brown-yellow, otherwise subshining dark brown. Marginal bristles rather numerous, strong, especially at margin of terga. Some silvery reflections occur particularly at base.

Hypopygium (Figs 1-4) brown. Cercus prolonged into pair of slender sickle-shaped lobes, with several distinct bristles medially, bare at tip (Fig. 2). Epandrial lamella rounded, with numerous strong, long bristles both on inner and outer faces (Fig. 1). Phallus hook-shaped at tip, hypandrium narrowly associated with phallus, almost paired, distinctly divided in two lamellae (Figs 3-4).

Length. Body $4.3 \mathrm{~mm}$, wing $5 \mathrm{~mm}$.

Female

Unknown.
Type material. Holotype, ơ, Gabon: Mvoum, Montagne de Sable, 1.-15.xi.1969, A. Villiers (MNHN).

Other material. $1 \delta^{*}$ in bad condition, Gabon: Ogooué, N'Gomo, 1906, P. Ellenberger (MNHN).

Etymology. From the Latin word "argentatus" meaning "silvery", in reference to the presence of silvery reflections on diverse body areas.

Distribution. Gabon.

Differential diagnosis. By its remarkable silvery pubescence, especially on the scutum, E. argentea cannot be mistaken with another species of the subgenus, although it resembles $E$. proboprocera by the posterior lengthening of the cerci, the weak development of the anal lobe of the wing and the absence of acrostichals.

\section{Empis (Disneyempis) hirsutipennis Smith, 1976}

Empis (Disneyempis) hirsutipennis Smith, 1976: 190.

Redescription of the female holotype

Species of medium size. Vein R4 prolonged, wings densely microtrichiate, metallic bluish to purplish reflections on abdominal terga $2-5$, and postabdomen modified (Fig. 6).

Head. Occiput dark brown with 1 distinct row of postocular bristles. Ocellar triangle with distinct but short pair of bristles. Frons and face black. Scape dark brown, pedicel and flagellomeres missing. Labrum long (3.5 times the head height), labium with characteristic annulations, labella brown, slender, bare, strongly sclerotised, labrum darker, palpus not visible. Eyes dichoptic, broadly separated on frons, lower ommatidia enlarged.

Thorax. Brown to dark-brown. Antepronotum with distinct lateral bristles. Postpronotal lobes with 1 distinct basal bristle. Scutum dark brown with brown minute pubescence especially laterally and posteriorly in the prescutellar depression. Acrostichals distinct, uniserial to irregularly biserial, dorsocentrals uniserial, rather strong, long. Two strong, long supraalars, respectively pre- and postsutural. Three strong, long notopleurals. One strong, long postalar. Scutellum brown, with 1 pair of strong, long apical bristles, 1 pair of fine, rather short subapicals.

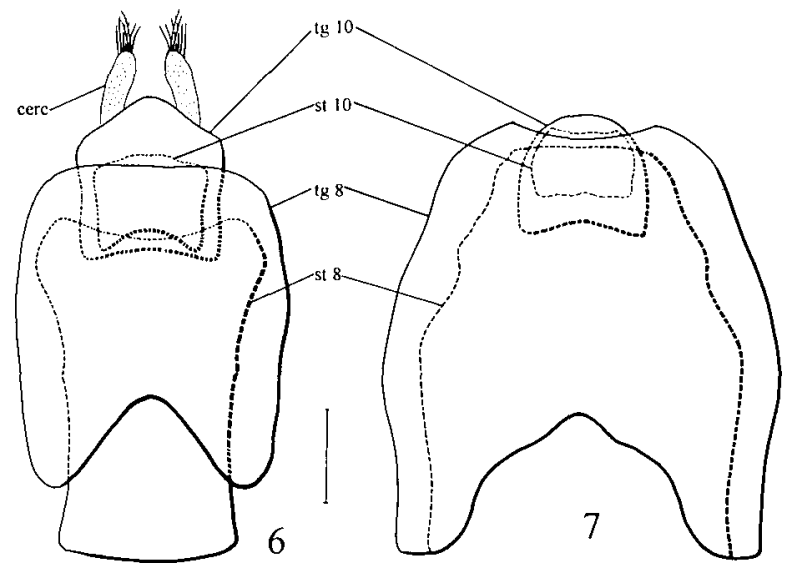

Figs 6-7.6-E. (D.) hirsutipennis Smith, female postabdomen in dorsal view, schematically (bristles omited except for cerci); $7-E$. (D.) sp. 1, female postabdomen in dorsal view (cerci and bristles omited). cerc - cercus; st 8 - sternum 8 ; st 10 - sternum 10; $\operatorname{tg} 8$ - tergum 8 . Scale: $0.2 \mathrm{~mm}$. 


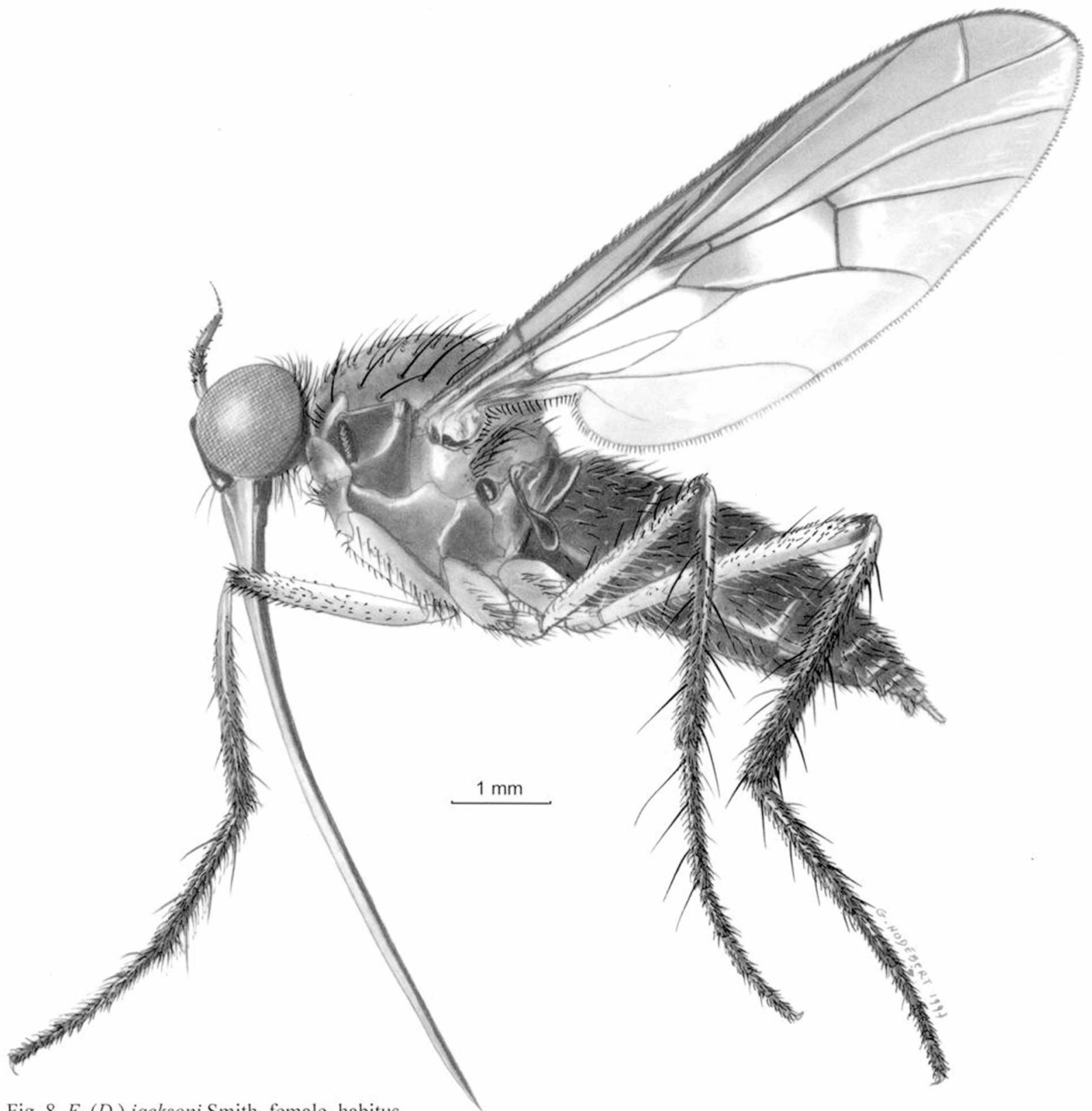

Fig. 8. E. (D.) jacksoni Smith, female, habitus.

Mesepisternum dark brown, mesepimeron brown. Laterotergite with fan of numerous strong, long bristles. Anterior and posterior spiracles black-brown.

Wing. Dark brown, densely microtrichiate especially in anal cell. Sc, M1 distinctly abbreviated, M2 evanescent at tip, other veins, including A1, complete. R4+5 of unusual shape: R4 very long, forming with R5 an acute angle. Anal lobe distinct but anal angle not very acute. Halteres with yellow base, dark-brown knob.

Legs. Fore coxa and femur yellow-brown, mid and hind femora yellow-brown, all tibiae and tarsi dark brown. Fore femur with few fine ventral bristles. Fore tibia with 1 row of short, rather strong dorsal bristles, numerous fine, short ventrals. First tarsomere of fore tarsi with rather long, strong ventral and dorsal bristles, other tarsomeres with distinct bristles at apex. Mid femur with short, rather fine ventral and dorsal bristles. Mid tibia with rather short dorsal bristles, fine ventrals, stronger and rather long at apical $1 / 4$, anterior face densely covered with numerous short bristles. First tarsomere of mid tarsi with
2 rows of strong dorsal bristles, other tarsomeres with distinct bristles at apex. Hind femur with numerous short anterolateral bristles especially in apical half. Hind tibia with 1 row of anterodorsal spine-like bristles, longer at apical $1 / 4,1$ row of spine-like posterodorsals only in basal half; anterior face of tibia densely covered with short spine-like bristles at basal half. First tarsomere of hind tarsi with 1 row of antero- and posteroventral bristles, longer posteriorly. Other tarsomeres with distinct bristles at apex.

Abdomen. Marginal bristles distinct. First tergum, basal part of second and last three terga brown, not shining. Other terga and posterior part of second shining, dark brown to metallic bluish to purplish. Postabdomen modified (Fig. 6): Tergum 8 with distinct desclerotised medioanterior part, enlarged; sternum 8 produced laterally beneath tergum; pleural membrane between tergum and sternum 8 entirely absent; cercus small, shorter and distinctly less sclerotised than usual, almost bare with few minute bristly setae at apex. 
Length. Body $6.3 \mathrm{~mm}$, wing $7.2 \mathrm{~mm}$.

Male

Unknown.

Type material. Holotype, $q$, Cameroon: West Cameroon, Lake Soden, 20.iv.1970, R.H.L. Disney (BMNH).

Distribution. Cameroon.

Differential diagnosis. E. hirsutipennis is characterised by the shape of the radial fork and the presence of densely microtrichiate wings. By its modified postabdomen (Fig. 6) and the peculiar pilosity of hind tibiae, it resembles an unamed species $E$. (D.) sp. 1 (Fig. 7).

\section{Empis (Disneyempis) jacksoni Smith, 1971}

Empis (Coptophlebia) jacksoni Smith, 1971: 86.

A very large species, with a long, rather fine bristle at apical tip of palpus, male cercus bifid at tip (Fig. 10).

Male

Head. Occiput black with fine, distinct postocular bristles. Ocellar triangle black, prominent, with 1 pair of distinct bristles. Frons black, never as wide as one ocellus at middle. Face dark brown, more than twice as wide as frons. Antenna black-brown, first flagellomere long, second and third flagellomeres as long as scape and pedicel together. Labrum very long ( 5 times the head height), labrum yellow-brown, labium with characteristic annulations, labella slender, bare, strongly sclerotised, palpus black, rather reduced, with 1 fine, long apical bristle. Eyes dichoptic, lower ommatidia enlarged.

Thorax. Antepronotum brown with rather strong bristles on each side. Proepisternum bare, prosternum with fan of distinct bristles. Postpronotal lobes brown with 1 strong, long basal bristle, several shorter anteriors. Scutum brown to dark brown. Acrostichals biserial, dorsocentrals biserial anteriorly, uniserial posteriorly, with 2 strong, very long prescutellar bristles. Two strong, long supraalars, respectively pre- and postsutural. Three strong notopleurals, 2 of which very long. One strong, long postalar. Scutellum brown with 2 strong, very long apical bristles. Laterotergite with fan of numerous bristles. Anterior and posterior spiracles dark brown to black-brown.

Legs. Coxae and femora yellow to yellow-brown, tibiae and tarsi black-brown. Fore femur without distinct bristles except for some dorsals. Mid and hind femora with antero- and posteroventral rows of fine, rather long bristles. All tibiae with 1-2 dorsal rows of strong, long bristles especially distinct apically. Fore and hind tibiae with only fine, short ventral bristles, mid tibia with 1 row of strong, long ventrals. Fore and hind first tarsomere, at least as long as four next tarsomeres together; former with strong, long dorsal and ventral bristles, latter with strong, short bristles except for a few dorsals which are slightly longer. First tarsomere of mid tarsi with 3 strong, long dorsal bristles. All other tarsal bristles short, sometimes very strong, spine-like.

Wing (Fig. 8) brown. Sc abbreviated, R4+5 branched at right angle. M1 and M2 evanescent towards the wing margin. Al complete. Anal lobe strongly developed, con-
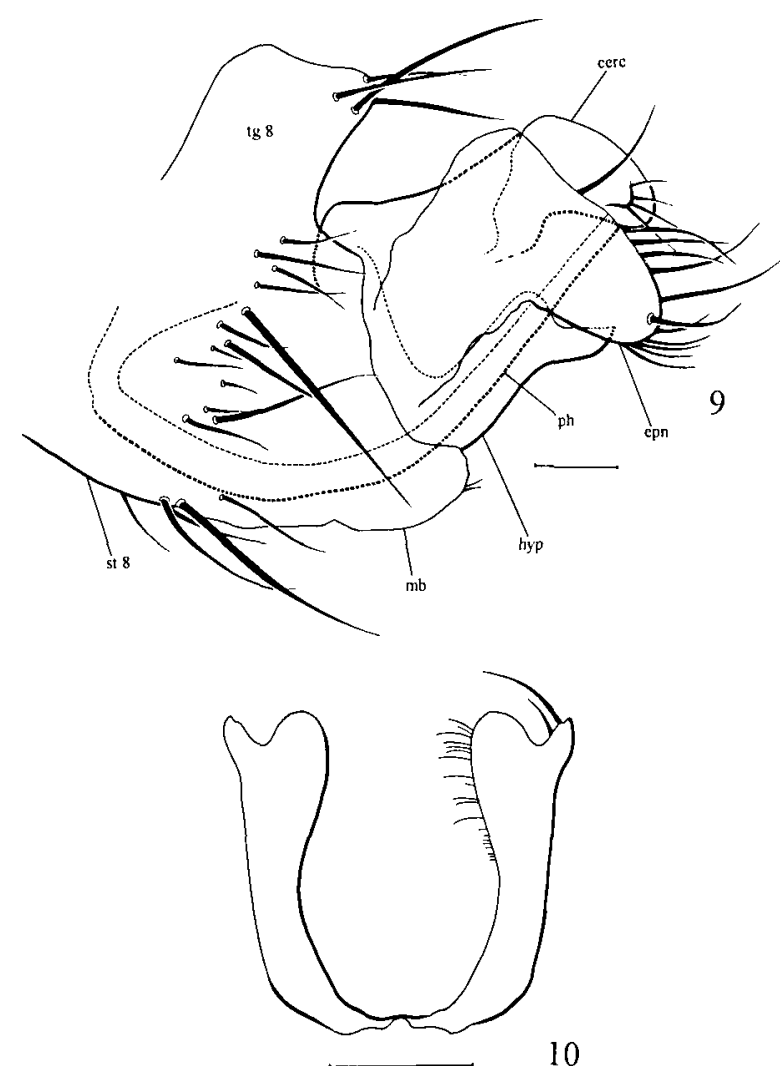

10

Figs 9-10. E. (D.) jacksoni Smith. 9 - male hypopygium in lateral view; 10 - cerci in dorsal view. cerc - cercus; epn epandrial lamella; hyp - hypandrium; mb - membrane of sternum 8 (here unfolded); ph - phallus; st 8 - sternum $8 ; \operatorname{tg} 8$ - tergum 8 . Scale: $0.25 \mathrm{~mm}$.

sequently anal angle very acute. Haltere with yellow base and stem, black knob.

Abdomen. Black-brown, not shining. Bristles well developed on first 2 terga especially laterally. Marginal bristles strong, rather long especially on terga. Sternum 8 with a membrane folded posteriorly (Fig. 9).

Hypopygium (Figs 9, 10). Cercus bifid apically, with numerous rather fine basoventral bristles as in $E$. spinifemorata. Epandrial lamella rounded at tip with strong, rather long dorsal and ventral bristles only in apical half. Hypandrium as in E. spinifemorata in shape and structure. Phallus rather thin, of usual shape for Disneyempis.

Length. Body 10-11.5 mm, wing 7.9-9 mm.

Female

Similar to male except for the following characters: Eyes broadly separated on frons, lower ommatidia enlarged. Frons almost as broad as face. Pilosity reduced especially on legs and abdomen. Abdomen with the first tergum brown, terga $2-5$ shining dark brown to metallic bluish to purplish reflections, terga $6-8$ and 10 brown to yellow-brown, neither metallic nor shining. Cercus longer than broad, dark brown, uniformly covered with fine, very short bristly hairs.

Length. Body 9.7-10.5 mm, wing 8.2-8.5 mm. 
Variation. One of the three studied females, probably newly emerged, lacks the metallic bluish to purplish abdominal reflections, with terga $2-5$ only shining brown.

Type material. Paratype, 10 , Democratic Republic of Congo: Beni, lturi Forest, ix.1946, T.H.E. Jackson (BMNH).

Other material. $2 \delta, 2 q$, Republic of Congo: Mayombe, Dimonika, 14.xi.1975, L. Matile (MNHN), $1 \delta^{*}, 19$, same but 12.xi.1975 (MNHN), 1o, Republic of Congo: route de Dimonika, à Dolisi, 26.xi.1968, J.P. Grillot (MNHN).

Distribution, Republic of Congo, Democratic Republic of Congo.

Differential diagnosis. $E$. jacksoni differs from all species of Disneyempis by its very large size. It resembles E. spinifemorata from which it differs in the form of the apically bifid male cercus and the absence of femoral spine-like projections in the male.

\section{Empis (Disneyempis) proboprocera sp. $\mathrm{n}$.}

Species of medium size. Acrostichals absent. Anal lobe of wing weakly developed. Epandrial lamella characteristic: developed and connected ventrally (Fig. 11).

Male

Head. Occiput and ocellar triangle almost invisible. Occiput dark brown with 1 row of postocular bristles. Frons very reduced, somewhat enlarged in triangle above antennae, black. Face dark brown, somewhat shining. Scape brown (twice length of pedicel), pedicel paler brown, first flagellomere dark brown, long (four times as long as pedicel), second and third flagellomeres black, as long as scape. Labrum very long $(5$ times the head height), yellow-brown, labium with characteristic annulations, labella slender, bare, strongly sclerotised, palpus reduced, dark brown, with distinct rather short apical bristle. Eyes only separated by narrow space, all ommatidia of equal size.

Thorax. Antepronotum not visible. Postpronotal lobes brown with 1 strong, long basal bristle and 5 finer, shorter anteriors. Proepisternum and prosternum yellowbrown, former bare, latter with 2 strong lateral bristles. Scutum dark brown. Acrostichals absent. Dorsocentrals uniserial, strong, very long, except for first pair. Intraalar absent. Two strong, long supraalars, respectively pre- and postsutural. Two strong, long notopleurals. Postalar calli with 1 strong, long bristle. Scutellum brown with 2 strong, very long apical bristles and 1 finer, shorter subapical bristle. Mediotergite brown. Laterotergite with fan of about 8 strong, long bristles. Anterior and posterior spiracles dark brown.

Legs. Fore coxa, femur and tibia yellow, mid and hind femora and mid tibia yellow, dark brown at apex. Hind tibia yellow at middle, otherwise brown, all tarsi dark brown. All femora with only short bristles. Fore tibia with row of 5 strong posterolateral bristles, 3 strong dorsals at apex. Mid tibia with distinct bristles only in apical half: 3 strong anterodorsals, 2 strong ventrals, 1 strong posteroventral and 2 others at tip. Hind tibia with 2 rows, respectively antero- and posterodorsal, of rather strong, long bristles, and with strong, more or less long ventrals. First tarsomere of fore tarsi very long, almost twice length of 4
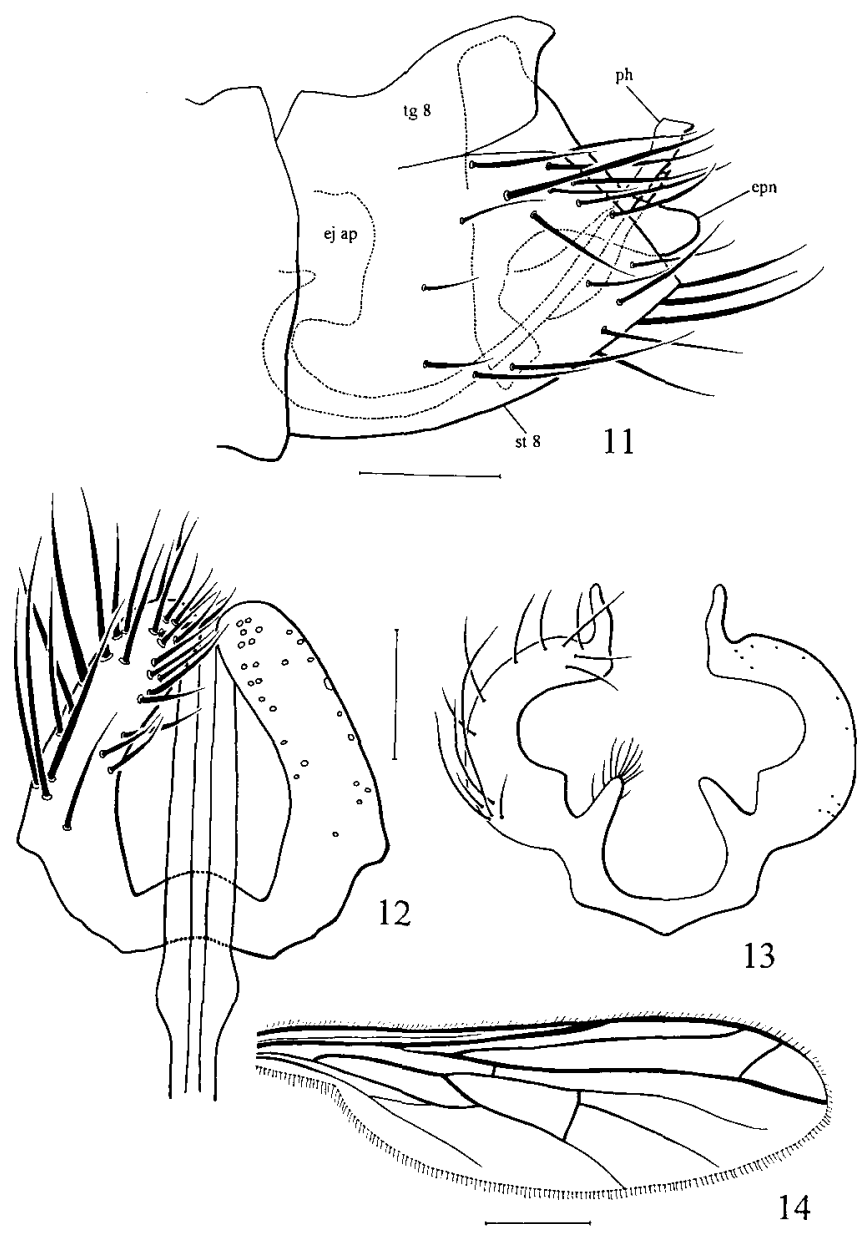

Figs 11-14. E. (D.) proboprocera sp. n. 11 - male hypopygium in lateral view (cerci and epandrial bristles omited); 12 epandrial lamellae, hypandrium and phallus in dorsal view; 13 - cerci in dorsal view; 14 - right wing. ej ap - ejaculatory apodeme; epn - epandrial lamella; ph - phallus; st 8 -sternum 8 ; tg 8 -tergum 8 . Scales: $11-13-0.2 \mathrm{~mm} ; 14-1 \mathrm{~mm}$.

remaining tarsomeres together. First tarsomere of mid tarsi with ventral spine-like bristles.

Wing (Fig. 14) dark brown. Sc distinctly abbreviated. Discal cell strongly truncate. M1 distinctly abbreviated, M2 abbreviated just before the margin of wing. Al complete but weakly sclerotised towards wing margin. Anal lobe weakly developed, consequently anal angle obtuse. Haltere entirely yellow.

Abdomen. First segment and anterior half of second yellow, otherwise terga dark brown, sterna brown. Strong, long marginal bristles on first 6 segments. Sternum 8 well developed posteriorly with numerous strong bristles at margin.

Hypopygium (Figs 11-13). Cercus of structure and shape close to E. argentea. Epandrial lamellae connected ventrally by unusual anteroventral expansion; dorsoapical tip of each lamella rounded, bearing numerous bristles. Hypandrium divided in two lamellae as in other Disneyempis.

Length. Body $6.6 \mathrm{~mm}$, wing $7 \mathrm{~mm}$. 
Female

Unknown.

Type material. Holotype, ð, Gabon: Mvoum, Montagne de Sable, 1.-15.xi.1969, A. Villiers (MNHN).

Etymology. A combination of the Latin words "probo-", for "proboscis", and "procera" meaning "lengthened".

Distribution. Gabon.

Differential diagnosis. E. proboprocera presents an exceptional character in the male genitalia: the ventral connection of epandrial lamellae, under the phallus. This character combined with the shape of male cercus, the entirely yellow halteres and the non-silvery scutum allow to distinguish this species from all other species of Disneyempis.

\section{Empis (Disneyempis) spinifemorata sp. $\mathrm{n}$.}

Species of medium size, characterised by the presence of 2 strongly sclerotised spine-like projections at the base of the male hind femora (Figs 17, 18).

Male

Head. Occiput black-brown, with 1 row of distinct postocular bristles. Ocellar triangle prominent, black, with pair of distinct bristles. Frons black shining, a little wider than one ocellus. Face lighter than frons in lower part, 1.5 times as broad as frons. Antenna black, first flagellomere somewhat lengthened. Labrum very long (more than 4 times the head height), labrum yellow-brown, labium with distinct characteristic annulations, prementum and labella brown, palpus dark brown with rather long, fine apical bristle. Eyes dichoptic, lower ommatidia a little enlarged.

Thorax. Antepronotum dark with distinct bristles. Postpronotal lobes brown-yellow with 1 strong, long basal bristle. Proepisternum and prosternum yellow-brown, latter with 4-5 distinct bristles. Scutum black-brown, not distinctly shining. Acrostichals biserial, rather short, dorsocentrals uniserial with 2 strong, long prescutellar bristles. Intraalar absent. Two strong, long supraalars, respectively pre- and postsutural. Two strong, long notopleurals. Scutellum with 2 strong, long apical bristles. Mediotergite brown. Mesepisternum brown to yellow-brown on lower half, mesepimeron yellow-brown. Laterotergite brown with fan of strong, long bristles. Anterior and posterior spiracles black-brown.

Legs (Figs 17, 18). Fore coxa yellow, mid and hind coxae brown. Femora yellow, tibiae yellow to brown and tarsi dark brown. Fore femur almost without bristles. Mid femur with distinct fine ventral bristles. Hind femur with some fine ventral bristles and more distinct dorsals apically. Base of hind femur with a strong pointed posterodorsal black spine-like projection (Fig. 17), and with a rather rounded posteroventral spine-like projection bearing brush of short bristly hairs (Fig. 18). Fore and mid tibiae with only short ventral bristles except for 1-2 strong, long bristles; 1 row of strong, long to very long dorsals. Hind tibia resembles mid tibia, ventral bristles distinctly more numerous. All tarsi with 1 row of about 10 strong, long dorsals as well as numerous ventrals

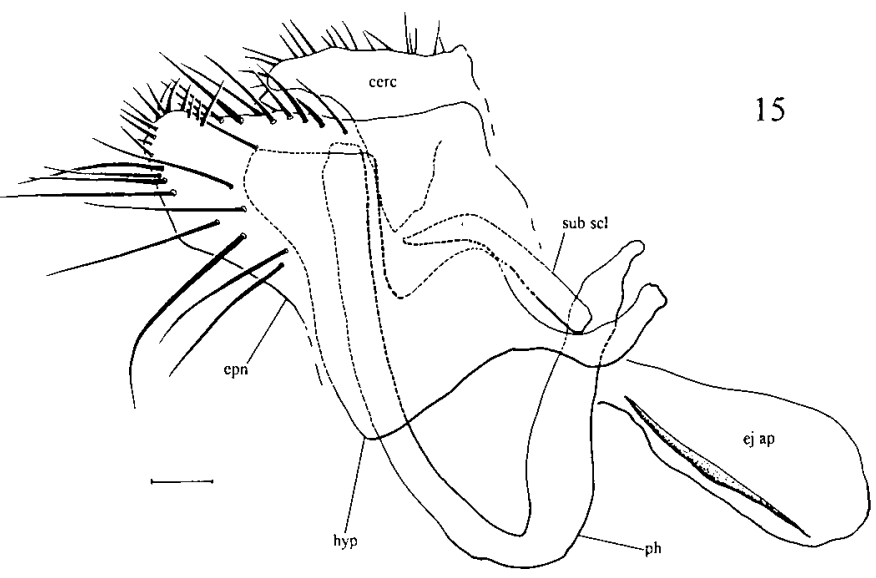

Fig. 15. E. (D.) spinifemorata sp. n., male hypopygium in lateral view. cerc - cercus; ej ap - ejaculatory apodeme; epn epandrial lamella; hyp - hypandrium; ph - phallus; sub scl subepandrial sclerite. Scale: $0.1 \mathrm{~mm}$.

which are very strong, shorter on first tarsomere of mid tarsi. First and second tarsomeres of mid tarsi with several very long, rather fine yellow-brown pennate bristles.

Wing brown. All veins complete except Sc distinctly abbreviated. R4 +5 branched at right angle. Discal cell strongly truncate. M1, M2 complete, less sclerotised towards the margin of wing. Al weakly sclerotised towards
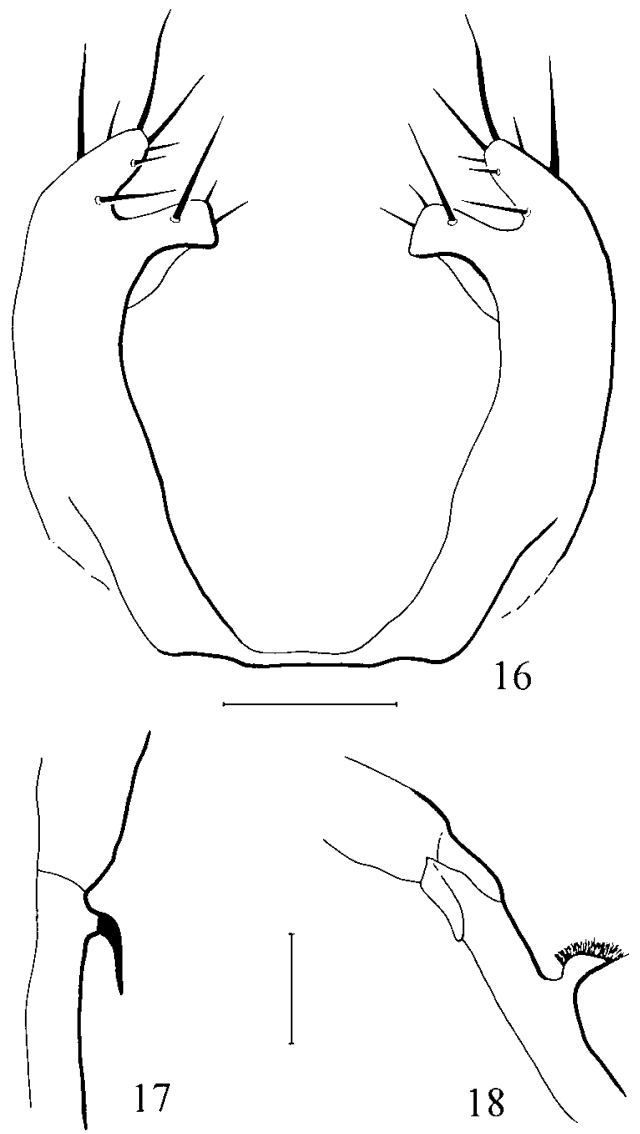

Figs 16-18. E. (D.) spinifemorata sp. n. 16 - male cerci in dorsal view; 17 - posterodorsal spine-like projection of male hind femur in dorsal view; 18 - posteroventral spine-like projection of male hind femur in lateral view. Scale: $0.1 \mathrm{~mm}$. 


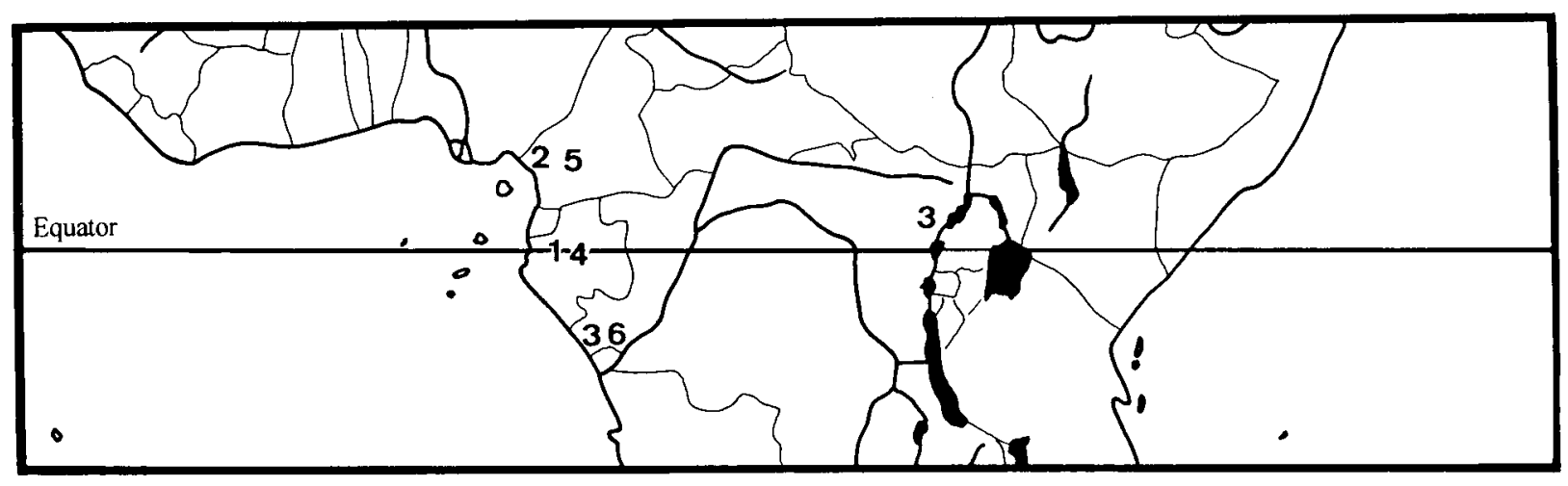

Fig. 19. Distribution of Disneyempis species. $1-E$. (D.) argentea sp. n.; $2-E$. (D.) hirsutipennis Smith; $3-E$. (D.) jacksoni sp. n.; $4-E$. (D.) proboprocera sp. n.; $5-E$. (D.) spinifemorata sp. n.; $6-E$. (D.) sp. 1.

the wing margin. Anal lobe well developed. Haltere with yellow-brown base, black stem and knob.

Abdomen. Brown to black-brown, somewhat shining on first tergum. Marginal bristles distinct especially on sides of terga.

Hypopygium (Figs 15, 16). Cercus of characteristic shape in dorsal view, with subapical, inner expansion, consequently apex bifid (Fig. 16), several distinct basoventral bristles with rounded tips towards subepandrial sclerite, especially well visible in caudal view. Epandrial lamella with numerous strong, long dorsal and ventral bristles, shorter at tip, especially interiorly. Hypandrium almost paired, well sclerotised, especially in apical half. Phallus length and shape characteristic of Disneyempis.

Length. Body 5-6.5 mm, wing 5.7-6.5 mm.

Female

Similar to male except for the following characters: Eyes more separated on frons, lower ommatidia enlarged. General pilosity of body shorter especially on legs and abdomen. Hind femur without basal spine-like projections. Terga 2-5 metallic with bluish to purplish reflections. Cercus longer than broad, uniformly covered with very short, fine bristly setae.

Length. Body 4.5-5.3 mm, wing 5.4-6.2 mm.

Variation. Two males, the holotype and one paratype, exhibit several very long, rather fine yellow-brown pennate bristles at tip of the first tarsomere and on the second one of the mid tarsi, whereas in the remaining males, three other paratypes, all bristles of the tarsi, although strong and also very long, are simple and black. The hypopygium of these five males appears identical and all males are considered conspecific; this difference is therefore viewed as a polymorphism related to the ornamentation of the midlegs. Alternatively, it is possible that the presence of one or the other character state is an anomaly as is often the case with other characters (for example wing venation).

Type material. Holotype, $\delta$, paratypes, $5 \delta, 7 \%$, Cameroon: West Cameroon, Kounden, Alt. 1,200 m, 12.viii.1967, L. Matile (MNHN).

Etymology. From the Latin words "spina" and "femur", in reference to the spine-like projections on male hind femur.

Distribution. Cameroon.
Differential diagnosis. E. spinifemorata resembles $E$. jacksoni but the latter is always distinctly larger, and the males have no femoral spine-like projections (cf. Figs 17, 18).

\section{Empis (Disneyempis) sp. 1}

Female

Diagnosis. Species of medium size with long labrum (almost 4 times the head height); prementum with characteristic annulations; legs distinctly bicolored with femora yellow, tibiae and tarsi dark brown; anterior face of female hind tibia covered with very short spine-like bristles; $\mathrm{M} 1$ and $\mathrm{M} 2$ complete but less distinct at tip; postabdomen strongly modified with tergum 8 medioanteriorly desclerotised, enlarged, sternum 8 developed laterally beneath tergum and cercus desclerotised, not longer than broad with a few bristly setae at tip only (Fig. 7).

Length. Body $7.5 \mathrm{~mm}$, wing $6.2 \mathrm{~mm}$.

Material. 1\%, Republic of Congo: Dimonika, 10.xi.1975, L. Matile (MNHN).

Distribution. Republic of Congo.

\section{KEY TO SPECIES OF SUBGENUS DISNEYEMPIS}

1 Acrostichals absent; anal lobe of wings weakly developed (Figs 5, 14); halteres entirely yellow; male cerci distinctly elongated posteriorly (Figs 2, 13); male eyes only separated by narrow space on frons; female unknown ........ 2

- Acrostichals present; anal lobe of wings more distinctly developed (Fig. 8); halteres with yellow base, black knob; male cerci not elongated posteriorly (Figs 10, 16); male eyes distinctly separated on frons; female abdomen with bluish to purplish metallic reflections on terga $2-5$, only shining brown in juveniles $\ldots \ldots \ldots \ldots \ldots \ldots \ldots \ldots \ldots$

2 White minute pubescence giving silvery reflections especially on scutum, fore coxae and mid tibiae; epandrial lamellae not connected ventrally; phallus hook-shaped at tip (Fig. 4) ................. E. argentea sp. n.

- Body without silvery reflections; epandrial lamellae connected ventrally; phallus simple at tip (Fig. 11) ........

E. proboprocera sp. $\mathrm{n}$.

3 Female postabdomen modified (Figs 6,7): tergum 8 with a distinct medioanterior desclerotised part, enlarged, sternum 8 produced laterally beneath tergum, pleural membrane between tergum and sternum 8 entirely absent; cerci small, not distinctly longer than broad, and distinctly less sclerotised; 
anterior face of hind tibiae densely covered with short spinelike bristles; male unknown $\ldots \ldots \ldots \ldots \ldots \ldots \ldots 4$

- Female postabdomen normal (Fig. 8): segment 8 as usual, cerci distinctly longer than broad, well sclerotised; anterior face of hind tibiae not densely covered with short spine-like bristles ....................... 5

4 R4 long, forming an acute angle with R5; wings densely microtrichiate (Smith, 1976: 193, Figs 1-2) ............ $\ldots \ldots \ldots \ldots \ldots \ldots \ldots$ E. hirsutipennis Smith

- R4 short, forming a right angle with R5; wings not densely microtrichiate $\ldots \ldots \ldots \ldots \ldots \ldots \ldots \ldots$....$\ldots \ldots$

5 Large-sized species (about $10 \mathrm{~mm}$ ); male with hind femora simple ................ E. jacksoni Smith

- Species distinctly smaller (about $5 \mathrm{~mm}$ ); male with two distinct spine-like projections at base of hind femora (Figs 17, 18) $\ldots \ldots \ldots \ldots \ldots \ldots \ldots \ldots$ E. spinifemorata sp. n.

\section{DISCUSSION}

Three pairs of species can be distinguished within Disneyempis. Firstly, E. argentea and E. proboprocera, two species with male cercus considerably prolonged, the anal lobe weakly developed and without acrostichals. Secondly, E. hirsutipennis and $E$. sp. 1, for which the presence of very short spine-like bristles on the anterior face of hind tibiae and the modified postabdomen in the female are very characteristic. Thirdly, E. jacksoni and E. spinifemorata, defined by the shape (bifid at tip) and the pilosity (numerous short basoventral bristles) of male cercus.

At present the lack of one sex in four species of Disneyempis (female unknown for E. argentea and E. proboprocera, male unknown for E. hirsutipennis and E. sp. 1) do not allow to establish accurately the relationships within the subgenus, especially between the abovementioned three pairs of species. Consequently, in order to analyze cladistically Disneyempis as well as to confirm its monophyly, the collect of additional specimens is needed.

ACKNOWLEDGEMENTS. For loan of type material and determined or undetermined specimens, I thank J. Chainey (BMNH, London), D.A. Barraclough and S. James (Natal Museum, Pietermaritzburg). I am indebted to L. Desutter-Grandcolas, P. Cranston, P. Grandcolas and L. Matile for reading this paper and for their helpful comments. This paper was also improved thanks to constructive criticism of K.G.V Smith, M. Chvála and B.J. Sinclair. The female habitus of $E$. jacksoni was drawn by G. Hodebert (MNHN, Paris).

\section{REFERENCES}

BEzZI M. 1909: Einige neue paläarktische Empis-Arten. Dtsch. Entomol. Z. 1909: 85-103.

ChvíLA M. 1994: The Empidoidea (Diptera) of Fennoscandia and Denmark. III. Genus Empis. Fauna Entomol. Scand. 29. $192 \mathrm{pp}$.

Cumming J.M., Sinclair B.J. \& Wood D.M 1995: Homology and phylogenetic implications of male genitalia in DipteraEremoneura. Entomol. Scand. 26: 120-151.

Daugeron C. 1997a: Découverte du sous-genre Xanthempis Bezzi en Afrique du Nord et description de trois espèces nouvelles (Diptera: Empididae). Ann. Soc. Entomol. Fr. 33: 155-164.
DAuglron C. 1997b: Notes sur le sous-genre Coptophlebia Bezzi et description d'une espèce nouvelle de France (Diptera: Empididae). Rev. Fr. Entomol. 19: 47-50.

DAUGLRON C. 1997c: Systématique phylogénétique et évolution du comportement chez les Empidides (Diptera: Empidoidea). Thèse du Muséum national d'Histoire naturelle, Paris, Tomes $1+2,301+123 \mathrm{pp}$.

Daugeron C. 1999: First Neotropical record of the genus Hormopeza Zetterstedt, 1838 (Diptera, Empididae). Zoosystema 21: $121-126$.

MCAL.PINE J.F. 1981: Morphology and terminology - adults. Chapter 2. In McAlpine J.F. et al. (eds): Manual of Nearctic Diptera. Vol. 1. Agric. Can. Monogr. 27. Agriculture Canada, Ottawa, pp. 9-63.

RAFAEL J.A. \& CUMming J.M. 1998: Monophyly and recognition of Macrostomus Wiedemann and Porphyrochroa Melander (Empididae; Empidinae). In Ismay J.W. (ed.): Abstracts Volume of the Fourth International Congress of Dipterology. Oxford, September 1998, p. 179.

Sinclair B.J., Cumming J.M. \& Wood D.M. 1994: Homology and phylogenetic implications of male genitalia in Diptera lower Brachycera. Entomol. Scand. 24: 407-432.

SinCLAIR B.J. 1995: New species of Hormopeza Zetterstedt from South Africa and Tasmania (Diptera: Empididae). Ann. Natal Mus. 36: 203-208.

Sмiтu K.G.V. 1967a: Results of the Lund University Expedition in 1950-1951. Diptera (Brachycera) Empididae. S. Afr. Anim. Life 13, pp. 217-233.

Smiti K.G.V. 1967b: Afrikanische Empididae (Dipt.). Stuttg. Beitr. Naturkd. No. 179, 16 pp.

Smit1 K.G.V. 1969: The Empididae of Southern Africa (Diptera). Ann. Natal Mus. 19: 1-342.

Smitı K.G.V. 1971: The sub-Saharan species of Rhamphomyia and Coptophlebia with abbreviated discal venation (Diptera: Empididae). Ann. Natal Mus. 21: 77-96.

SMITI K.G.V. 1976: An unusual new species representing an undescribed subgenus of Empis L. (Dipt. Empididae) from Africa. Entomol. Mon. Mag. 111: 189-193.

Sмiтh K.G.V. 1980: Family Empididae. In Crosskey R.W. et al. (eds): Catalogue of the Diptera of the Afrotropical Region. British Museum (Natural History), London, pp. 431-442.

SyrovítKA O. 1991: Revision of H. Loew's and T. Becker's types of Empis s. str. species (Diptera, Empididae) in the Berlin and St Petersburg Museums. Mitt. Zool. Mus. Berl. 67: 225-278.

WIEgmann B.M., MitTer C. \& ThOMPson F.C. 1993: Evolutionary origin of the Cyclorrhapha (Diptera); tests of alternative morphological hypotheses. Cladistics 9: 41-81.

Appendix. Material examined. The region where the group is distributed (AFR - Afrotropical, AUS - Australasia, ORI - Oriental, PAL - Palaearctic) and the corresponding reference are indicated in parentheses and in square brackets respectively. Although the phylogenetic and taxonomical treatment of Afrotropical groups will be detailed in several papers to come, their monophyly is tentatively defined following Daugeron (1997c). $\left.{ }^{*}\right)$ denotes uncertain monophyly.

Genus Empis L. subgenus Disneyempis Smith (AFR)

Genus Empis L. subgenus Coptophlebia Bezzi albinervis-group (PAL) (Chvála, 1994)

bivittata-group (AFR) (Daugeron, 1997c). A group of nine species only distributed in South Africa, defined on the basis of a massive and apically bifid hypandrium.

chrysocera-group (AFR) (Daugeron, 1997c; in prep.). A group of ten species widely distributed in Africa, defined by the anterior connection of epandrial lamellae and the division of 
cerci into two lobes. Two complexes of species can be distinguished in the chrysocera-group based on modifications in male pregenital segments.

hyalipennis-group (PAL) (Chvála, 1994; Daugeron, 1997b, c) vitripennis-group (PAL) (Chvála, 1994)

namwamba-group (AFR) (Daugeron, 1997c). A group of at least 13 species, widely distributed in Africa, defined by the presence of two fine strongly sclerotised hypandrial expansions.

$X$-group (AFR, AUS, ORI) (Daugeron, 1997c). A widely distributed group of at least five undescribed or undetermined species from Afrotropical (2 species), Oriental (2 species) and
Australasian ( 1 species) regions, tentatively defined on the basis of an unpaired epandrium.

Genus Empis L. subgenus Empis s. str.

chioptera-group (PAL) (Syrovátka, 1991)

*nigripes-group (PAL) (Syrovátka, 1991)

pennipes-group (PAL) (Syrovátka, 1991)

*setitarsus-group (AFR) (Daugeron, 1997c). A group of at least 13 species, mainly distributed in South Africa, for which the monophyly remains uncertain.

Genus Rhamphomyia Meigen subgenus *Aclonempis Collin (PAL)

Received March 19, 1999; accepted August 2, 1999 